


\section{O choque do real em Amarelo manga}

\section{The shock of the real in} Mango yellow

\section{Gilka Padilha de Vargas' $[7$}

PORTO ALEGRE | v. $19 \mid$ n. 31 | 2014 | pp. 96-106 Sessões do Imaginário

\section{Resumo}

A partir das reflexões da pesquisadora Beatriz Jaguaribe e tendo como corpus as sequências Abertura Wellington, $\mathrm{O}$ homem perdidoe Abatedoboinomatadouro, do filme Amarelo manga, este artigo visa apontar algumas das escolhas estéticas realistas que 0 diretor Cláudio Assis utiliza para sensibilizar - espectador, engendrando de forma estratégica elementos da linguagem cinematográfica para realçar, intensificar e exacerbar cenas da violência urbana cotidiana que, normalmente, passariam despercebidas, produzindo o que Jaguaribe nomeia como "choque do real".

\section{Palavras-chave}

Choque do real; cinema; Amarelo manga.

\section{Abstract}

From the reflections of the researcher Beatriz Jaguaribe and having as corpus the sequences Opening Wellington, The lost man and Slaughter of cattle at the slaughterhouse, from the movie Mango yellow, this article aims to highlight some of the realistic aesthetic choices that the director Cláudio Assis uses to sensitize the viewer, engendering a strategic elements of film language to enhance, intensify and exacerbate scenes of everyday urban violence that usually go unnoticed, producing what Jaguaribe names as "real shock".

\section{Keywords}

Real shock; cinema; Mango yellow. 
Vivemos um momento histórico no qual somos bombardeados por imagens. As cidades estão repletas de outdoors; muros são cobertos por cartazes; vitrines nas quais o produto principal é quase que ocultado pelos estímulos visuais que o circundam dentro da pequena (sim, torna-se pequena!) caixa de vidro que deveria expô-lo são um pequeno exemplo da poluição visual a qual estamos submetidos. Na televisão, o espectador vê imagens em ritmo acelerado e se esforça em acompanhá-las para entender o que pretendem narrar. É dessa maneira que recebe as imagens da miséria social que assola o mundo, inclusive o Brasil: imagens de guerras, grandes incêndios, grandes catástrofes naturais, sequestros, assassinatos. São comuns reportagens nas quais a imagem de cadáveres é tratada digitalmente para não chocar o espectador, mas os corpos estão lá, estendidos no chão, e no canto da tela está destacada a mensagem "Ao Vivo". Basta acessar a Internet e visualizar imagens de corpos humanos (crianças ou adultos) destroçados, cenas de sexo, animais sendo mortos das mais diversas maneiras, seres humanos vivendo e/ou sobrevivendo por entre escombros, em acampamentos de refugiados ou na miserável periferia de alguma grande metrópole. Há o acesso irrestrito a imagens reais e fortes.

Como uma produção cinematográfica consegue tocar olhares já tão acostumados à tragédia, à miséria, ao sangue - humano ou não -, à violência em geral? Como, então, encontrar maneiras de sensibilizar o espectador/leitor ou mesmo desestabilizar sua neutralidade?

A pesquisadora brasileira Beatriz Jaguaribe (2007), em seu livro $O$ choque do real: estética, mídia, cultura afirma que nos grandes centros metropolitanos brasileiros existe uma cultura do medo, resultado da experiência urbana, das vivências pessoais da ocorrência de assaltos, sequestros, crimes diversos, e também dos imaginários midiáticos, das produções literárias, televisivas, cinematográficas que divulgam estas notícias, criam histórias, personagens e crimes. Nos cenários de incerteza urbana, "a produção de retratos contundentes da realidade em viés realista funciona como uma 'pedagogia do real' e da realidade que potencializa narrativas de significação em tempos de crise" (Jaguaribe, 2007, p. 99).

Para ela, grande parte da população brasileira absorve a realidade social engendrada pela mídia, pois "o predomínio do realismo cotidiano torna-se um código comunicativo" (Jaguaribe, 2007, p. 112). A realidade produzida pelas imagens e narrativas midiáticas, constante e intensamente exibidas e recebidas, torna-se importante fonte de constituição de mundo para a grande maioria dos brasileiros. A associação "frágil escolaridade / predomínio da cultura audiovisual" proporciona que os novos códigos realistas também funcionem como diagnósticos da nossa vivência social.

A "ficcionalização da realidade na reportagem e o efeito de realidade na ficção [...] fabricaram a percepção do cotidiano" (Jaguaribe, 2007, p.109). Reportagens jornalísticas, fotojornalismo e programas ao vivo, sustenta a autora, saciam o povo com o espetáculo dramatizado da realidade. Frente a esta saturação midiática, surgem as estéticas do realismo como resposta de choque e também como uma forma de aperfeiçoar a ligação "entre experiência e representação, na tentativa de produzir vocabulários de reconhecimento na incerteza tumultuada das cidades do Brasil" (Jaguaribe, 2007, p. 120).

Talvez essa visão de "mundo real" seja falseada para alguns olhares, ou até mesmo exagerada por motivos ficcionais, mas, para outros, a imagem é apenas a tradução, a captura de momentos concretos, e reais, daquele espaço. Assim, a representação de um discurso atribuído a essas camadas sociais lida com verdades contingentes. Porém, o discurso subjacente dos filmes é contundente. A luta pela sobrevivência, a violência e as manifestações de um contexto sem a intervenção de outros grupos socioeconômicos (Gasparelli Júnior, 2008, p.123).

O "choque do real" no cinema e na literatura, conforme coloca Jaguaribe (2007), é produzido pelas estéticas do realismo com o objetivo de dar conta das conflitivas experiências da modernidade urbana no Brasil. Os diferentes códigos do realismo se utilizam do que Roland Barthes (2002) chamou de "efeito do real" para realizar diversas abordagens da vida social, experiência e interpretação da realidade.

Para Jaguaribe (2007), "choque do real" está extremamente ligado à ideia de "efeito do real". Existem aspectos que influenciam na sua criação, tais como o momento histórico, os materiais e os suportes técnicos empregados enquanto meios para a representação, dependendo também da evocação de noções culturalmente construídas da realidade. Para ela, "o impacto dos registros realistas depende dos poderes persuasivos do 'efeito do real' e de sua 
capacidade de oferecer narrativas e âncoras visuais de significação em cenários urbanos fragmentados pela incerteza, violência e desigualdade social" (Jaguaribe, 2007, p. 104)

Jaguaribe define o "choque do real" como "a utilização de estéticas realistas visando suscitar um efeito de espanto catártico no leitor ou espectador" (2007, p.103), sensibilizando-o ou provocando incômodo sem, entretanto, apelar para registros de algo grotesco, sensacionalista ou espetacular. Quando a autora fala sobre espanto catártico, refere-se ao "choque do real" relacionado a ocorrências cotidianas, históricas e sociais, sendo o efeito catártico elaborado a partir de elementos do dia a dia e não de ocorrências catastróficas.

[...] o "choquedoreal" [é] um momentode intensificação catártica onde uma situação extrema, seja de violência, terror, pobreza ou paixão é aguçada de forma tão verossímil que o leitor/espectador é tomado pela ficcionalidade e suspende seu julgamento. O choque se potencializa quando uma realidade que é ignorada ou absorvida mecanicamente tornase, por instantes, vívida e insuportável. Para que o "real" apresentado choque, é preciso que ele seja convincente e diverso do vocabulário e das imagens sensacionalistas, usualmente exibidas nas mídias que saciam os anseios do grande público pelo "pão e circo" (Jaguaribe, 2003, on-line).

Para a autora (2007), o criador artístico se utiliza do "choque do real" procurando fazer com que o espectador/leitor saia de sua neutralidade, busca provocar espanto, estimular sentimentos críticos e denúncias sociais. Conforme suas colocações, o choque torna-se efetivo quando desfere o pancadão do "efeito do real" que aguça a verossimilhança realista produzindo tanto uma desestabilização quanto um veredicto sobre a realidade cotidiana (Jaguaribe, 2003). Para que o "choque do real" seja produzido, além do efeito catártico, deve gerar também um estranhamento sobre o espectador/leitor. Em relação ao estranhamento, Jaguaribe (2007) se refere ao evocado por Sklorskiji, que deriva da intensificação da percepção que retira o caráter de costumeiro, revelando o caráter de desfamiliarização.

Em relação ao espectador/leitor, nos diz que ele é único; cada um recebe e processa de maneiras diversas a mesma descrição realista de um filme ou livro. A recepção do "choque" não pode ser medida, pois o impacto de tal efeito realístico varia segundo o contexto histórico e as bagagens cultural e social de cada indivíduo. $O$ dispositivo catártico é por vezes ambíguo, sendo esta ambiguidade resultado da própria relativização de valores e da perplexidade quanto ao significado da experiência.

Discorrendo sobre as diversas estéticas do realismo, coloca que são formas culturalmente engendradas de fabricação da realidade, podendo oferecer retratos críticos da "experiência do mundo" por proporcionarem à "realidade" tornar-se "real". A capacidade de organizar narrativas e imagens, de modo a oferecerem uma "intensidade" do real maior do que o fluxo disperso do dia a dia, fabrica uma realidade plena de "efeito do real".

[...] a força do realismo estético reside na sua capacidade de fornecer vocabulários de reconhecimento na experiência contemporânea. Valendo-se de representações de intensidade dramática, de narrações do desmanche social, os novos códigos realistas fornecem uma pedagogia da realidade de fácil acesso para leitores afastados dos cânones letrados (Jaguaribe, 2007, p. 12).

Em entrevista a Luiz Zanin, em 2007, para o blog Cinema, cultura \& afins, Jaguaribe afirma que mundos plausíveis são criados pelo uso da ficção e de recursos de intensificação dramática. É através do uso do senso comum cotidiano, apoiado na verossimilhança, que estas representações engendradas pelos códigos realistas são capazes de fornecer vocabulários de reconhecimento que reforçam o desnudamento da realidade. As estéticas do realismo criam ficções que intensificam, selecionam e enquadram eventos, personagens, enredos, retratando de maneira crítica e contundente as mazelas do social.

[...] o que marca a produção recente é o forte apelo ao retrato da realidade em face da violência urbana. Favelas, centros correcionais, periferias urbanas carcomidas, prisões infectadas e a saga dos traficantes são alguns dos tópicos abordados. A despeito da variedade de códigos e registros, esses relatos ficcionais e documentais realistas constituem também uma resposta às fabricações televisivas do "real" (Jaguaribe, 2007, p.110)

Em quais imagens e narrativas contemporâneas podemos encontrar o "pancadão do real"? Conforme a autora (2007), o cinema do "choque do real" pode ser encontrado em diversas produções nacionais contemporâneas: Cidade de Deus (Fernando Meirelles, 2002), Carandiru (Héctor Babenco, 2003), 0 invasor (Beto Brant, 2001), Ônibus 174 (José Padilha, 2002) e Amarelo manga (Cláudio Assis, 2003). 
Os novos registros realistas e hiper-realistas na literatura e cinema brasileiros, mesmo apresentando certa pedagogia da revelação da realidade, não mostram preocupação em estabelecer retratos da consciência nacional, mas simrealçara precariedade, as contradições e a marginalização nas grandes metrópoles do país. Através do naturalismo brutal, das histórias sórdidas do realismo sujo das ruas, da saga das situações-limite, as produções contemporâneas atendem às expectativas do grande público oferecendo o pancadão do "choque do real". Jaguaribe (2007) argumenta que filmes como Cidade de Deus, Amarelo manga e Carandiru constituem um cinema visceralmente marcado pela presença do naturalismo tipificante em detrimento da nuance psicológica do realismo. $O$ naturalismo atualizado continua enfatizando fortemente a vivência do corpo, os instintos e as ações impulsionadas pelos desejos. Nele, personagens são determinados por um delineamento inicial de desejos, atuando, portanto, sem maiores questionamentos.

A produção realista brasileira apresenta, recentemente, narrativas e filmes que exploram as "contradições, as expectativas, os desejos e frustrações de vidas que não buscam transformações coletivas [...] retratam [...] a intensidade, tragédia e impasse de histórias de vida de pessoas que não podem viver além dos fragmentos do presente" (Jaguaribe, 2007, p.108). Esses filmes enfatizam como a mídia se torna real e a vida se ficciona; como a presença da câmera ativa acontecimentos e como o sentido do real é obtido por meio de recursos dramáticos da mídia visual. Retratam de maneira crítica a exclusão social, mostrando vidas precárias, miseráveis, potencializando a fala e a expressão destes anônimos que jamais chegarão à visibilidade midiática.

Dentre estes filmes, enfocaremos Amarelo manga, por consideramos que se trata de uma produção na qual o choque do real é muito bem engendrado por seu diretor.

O real e a realidade importam porque pautam nossa possibilidade de significação do mundo. Importam também porque o real e a realidade são arduamente contestados e fabricados. Num mundo de realidades em disputas, as estéticas do realismo no cinema, fotografia e literatura continuam a ser conclamadas a oferecer retratos candentes do real e da realidade, são acionadas a revelar a carne do mundo em toda sua imperfeição (Jaguaribe, 2007, p. 41).

E é parte da "carne do mundo em toda sua imperfeição" que nos apresenta Amarelo manga, primeiro longa-metragem do diretor pernambucano Cláudio Assis, lançado em 2002. Conforme coloca Alencar (2008), Assis direciona o olhar do espectador para a decadência, estruturando um retrato de abandono, como se Recife tivesse perdido seus encantos. A intenção de mostrá-la como um quebracabeça sujo e deteriorado é reforçada pelo não visto: nenhuma imagem agradável ou turística, nenhuma praia. O diretor se coloca diante da cidade de modo objetivo, buscando apreendê-la em seu registro mais duro. Mais do que apresentar a realidade, mostra uma concepção sobre o que é esta realidade.

O diretor pernambucano fala sobre este aspecto de seu trabalho em entrevista à Contracampo:
[...] tenho uma tendência a tratar as questões de frente, de cara, mostrar como a vida é, de preferência com questões ligadas ao povo, com as minhas idéias. Esse é meu universo, o meu caminho; isso é que bate na minha cabeça, sem visões românticas e idealizadas (Assis, 2003, on-line).

É início do dia. Homens e mulheres começam mais uma jornada. As ruas mostradas estão sujas; as casas, em estilo colonial, antigas e mal cuidadas; passamos por favelas, pontes sobre o rio que atravessa a cidade. Pequenos e pobres estabelecimentos comerciais têm suas portas abertas; bicicletas servem para transportar o ganha pão de alguns; caminhonetes se transformam em ponto de venda de cachorro-quente; frutas são transportadas e embaladas para a venda. Seres humanos simples escovam os dentes na sacada do segundo andar de uma casa que um dia foi imponente e iniciam mais um capítulo de sua batalha pela sobrevivência. Esta é a Recife que Assis mostra a partir de cenas documentais mescladas ao trajeto realizado pelo personagem Isaac em seu velho Mercedes amarelo, ao som de uma rádio que fala sobre a cidade, os crimes que nela ocorrem e suas mazelas sociais.

A câmera descortina, esquadrinha e espia a cidade e seus personagens em sua jornada diária, retratando-os despudoradamente. Através de closes, travellings, movimentos lentos, o diretor aproxima ou distancia o espectador; proporciona que este se sinta dentro da cena ou seguro e protegido, resguardandose "voyeristicamente", com o tempo necessário e suportável para que reconheça nestas cenas uma realidade bem presente em todas as grandes cidades brasileiras. 
Cláudio Assis, em entrevista para Revista de Cinema (2011, on-line), afirma: "eu filmo a vida como ela é". Fonseca (2006, p.102) refere que o nível documental acaba por reforçar o clima realista dos ambientes nos quais os personagens circulam, transformandoos em parte desses ambientes, parte desse mundo histórico, provocando no espectador a sensação de que, por compartilhar esse mesmo universo, qualquer pessoa mostrada nas cenas documentais poderia ser personagem do filme.

Para Alencar (2008, p.175), o realismo do filme tem seus alicerces na ideia compartilhada e difundida pelos meios de comunicação de massa e até mesmo pelo cinema, de que o nordeste do país vive em absoluta pobreza, com o sofrimento de seu povo assumindo traços de fatalidade. Segundo colocação de Frus (1994, p. 26), realismo "não é o que nos dá uma documentação factual ou completa, mas o que produz uma ilusão do mundo que reconhecemos como real".

O realismo estético é bem engendrado por Assis quando mostra em suas cenas documentais a periferia de Recife com suas favelas, ruelas sujas e gente simples de pele curtida em suas atividades diárias, mesclandoas às cenas ficcionais. Conforme aponta Alencar (2008, p.174), o realismo de Amarelo manga apoiase, principalmente, neste material que traz das ruas. Com isto, confere maior peso à diegese, constituída de forma coerente e verossímil. Jaguaribe (2007, p. 12) complementa essas colocações dizendo que "o realismo estético, [...] produz retratos da 'vida como ela é', [...] faz uso da ficção e de recursos de intensificação dramática para criar mundos plausíveis que forneçam uma interpretação da experiência contemporânea".

Em entrevista concedida a Cléber Eduardo, Assis afirma que "[...] a gente tem uma violência nossa, cotidiana, dentro da nossa própria casa, que é tão violenta quanto filmes de Hollywood. Queria fazer um filme sobre essas pequenas violências, que fosse poético e violento ao mesmo tempo" (2003, on-line.).

O que o espectador recebe então, é um filme que reflete a caótica urbanidade que lhe deu origem ${ }^{3}$, sem julgamentos morais, culpas, preocupações com correção política e parte "para um tratamento de choque sem pudor com os exageros, assumindo sua irreverência incômoda [...]", conforme coloca Figueiroa (2007, p.5). Para Jaguaribe (2007), o efeito crítico ocorre pela chocante retratação do desmanche social e não pelo questionamento do mundo ou pelo relevo psicológico dos personagens.

A "realidade" bruta, sórdida, violenta e desigual choca, mas também canaliza a percepção para vocabulários específicos de interpretação e códigos estéticos de fácil apreensão [...] o filme Amarelo manga reatualiza vocabulários do naturalismo em nova formatação fílmica ao contar, com enquadramentos criativos de câmera, as vidas estreitas e sórdidas dos pobres no Recife (Jaguaribe, 2007, p. 123).

Cláudio Assis, em entrevista para a revista Contracampo (2003, on-line.), argumenta que seu filme é difícil, trata da miséria humana e "se não buscarmos uma elegância no movimento de câmera, no enquadramento, no desenho das cenas, fica um negócio feio e podre". Falando sobre este aspecto, Alencar (2008, p.194) coloca que, apesar de a direção de fotografia estabelecer uma forte beleza formal, "em nada reduz a dureza de suas imagens e a sensação de incômodo que elas estão, propositadamente, dispostas a provocar".
Jaguaribe (2007) comenta que enfatizando aspectos pouco usuais, formas inovadoras do realismo alcançam a produção de um retrato inquietante da realidade. Para a autora (2003), a escolha estética de Assis pode ser vista como um modo de retratar a violência urbana nas grandes cidades diferente da utilizada nas mídias, com imagens apelativas e sensacionalistas, diária e massivamente mostradas. O diretor se preocupa em apresentar o cotidiano de forma elegante, com esmero técnico e imagens bem construídas, inserindo cenas documentais nas ficcionais sem, entretanto, tornar esta realidade menos contundente ou realisticamente brutal. Estrategicamente, segundo a autora (2007), o cineasta exacerba o real e a realidade através destas imagens belas e elegantes; ao mesmo tempo, causa desconforto pela maneira como sua câmera retrata o sangue, a sujeira - as cores e texturas que denunciam a passagem do tempo, o descaso, o abandono, a falta de higiene, a violência.

Em Amarelo manga, são várias as cenas nas quais Assis desfere o "choque do real". Dentre elas, vemos Isaac experimentando indizível prazer ao atirar num cadáver; Kika, de forma quase selvagem arrancando com os dentes a orelha da amante de seu marido; Dona Aurora, causando espanto ou estranhamento ao masturbar-se com seu nebulizador.

Para cotejarmos o trabalho do cineasta com a teoria exposta, principalmente, de Beatriz Jaguaribe, enfocaremos apenas três delas, por ordem de aparição no filme. Estas cenas foram escolhidas por utilizarem estratégias diferenciadas para provocar o espanto catártico. A primeira, a apresentação do personagem Wellington, pela forma como a câmera mostra ao espectador a brutalidade, a sujeira, a violência; a segunda, na qual Lígia mostra seus amarelos pelos 
pubianos a Isaac, por trazer para a tela o estranhamento, a desfamiliarização citada por Jaguaribe; a terceira, o abate do boi, que retrata de forma documental os detalhes de como o animal é violentamente abatido e, também, sua agonia.

\section{Sequência 04 - Abertura Wellington ${ }^{4}$}

Um homem [...] está com um quarto de boi sobre uma mesa de madeira num velho frigorífico. Descobrimos que o som do bate estaca é o homem partindo o boi com um facão e um porrete. Ele está vestido com pesadas roupas e galochas brancas. Um avental de plástico, também branco, cobre sua barriga. A seu lado um companheiro de profissão o acompanha no serviço. A câmera mostra detalhes da carne avermelhada. [...] Wellington fala sobre a vida e sobre sua esposa (Lacerda, 2002, p. 5).

A sequência inicia com um plongée (Figura 1), conduzindo o olhar do espectador em travelling, oferecendo uma visão topográfica do espaço e descortinando lentamente o ambiente, preenchendo o quadro com animais mortos enfileirados um ao lado do outro, esquartejados por homens também sujos de sangue, um chão repleto de sangue, vísceras, descartes bovinos e pedaços de tecidos sujos. Wellington se encontra desmembrando uma carcaça bovina, partindo-a ao meio a golpes de machadinha, como alguns de seus colegas. Enquanto trabalha, conversa com um companheiro que está limpando outra carcaça com um pedaço de tecido já escurecido. Apenas ele fala.

Vemos uma figuração caracterizada com camisetas, bermudas, chinelos, que trabalha, conversa, perambula por entre os animais mortos. A câmera se aproxima do personagem que fala sobre a morte, a razão de seu apelido (já matou um homem), como sua esposa Kika é crente e como acredita mais nela do que em si. Lentamente e na altura dos olhos, a câmera na mão se aproxima do personagem, chegando à lateral para mostrar seu rosto no momento em que pronuncia seu nome: Wellington Canibal. Ainda na mão, a câmera acompanha o diálogo dos dois homens e, por fim, movimenta-se em plano aberto, caminhando pelo espaço cenográfico. É importante assinalar que as câmeras laterais estão aqui como o ponto de vista de
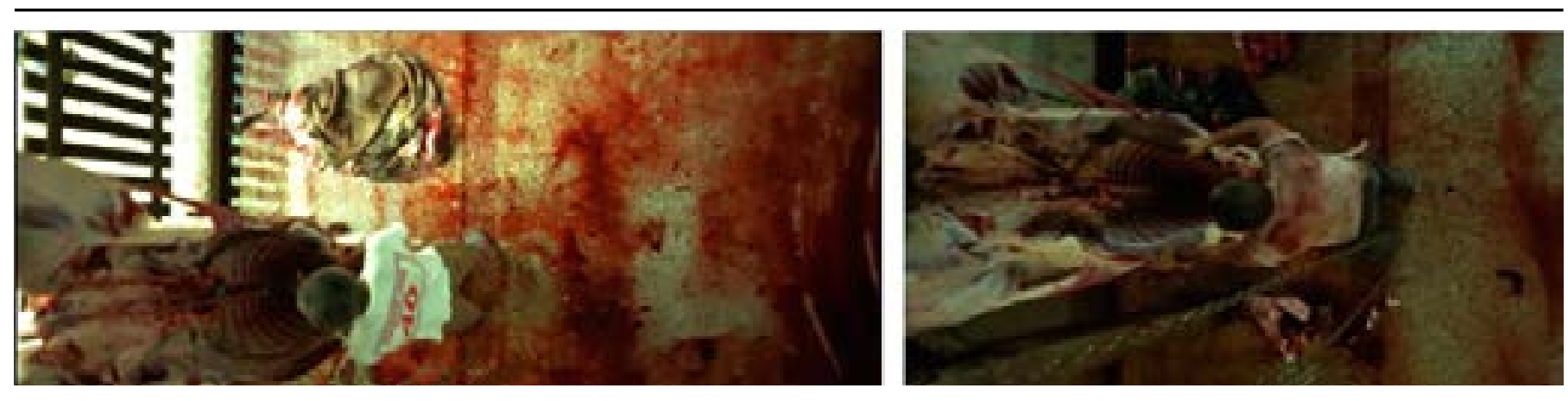

Figura 1:

Plongée na sequência Abertura Wellington um observador, um olhar quase documental, o que se intensifica quando, no plano mais aberto, a câmera proporciona ao espectador caminhar próximo às carcaças. Temos os dois opostos citados anteriormente por Jaguaribe: a câmera inicial que oferece a segurança de vermos do alto, afastados da cena e de sua violência e a câmera final, que praticamente permite ao espectador sentir o odor da locação ou ter a sensação de que basta mover a mão para tocar as carcaças - ou seja, inserido na violência.

Ao invés de um velho frigorífico com dois trabalhadores uniformizados e parte de uma carcaça, como era a ideia original do roteiro, o cineasta realça ainda mais a realidade que deseja mostrar aumentando o espaço, o número de figurantes, de carcaças e atribuindo ao lugar um ar de clandestinidade, de trabalho informal.

Para apresentar Wellington, acrescenta aos seus movimentos de câmera e planos uma gama de informações, como o vermelho da carne, do sangue, das roupas tingidas por ele, que aparece em toda a sua plenitude e inunda a tela; a textura das paredes de uma construção antiga, colonial: sujas, com a pintura desfeita. Essas são as estratégias que Assis utiliza para retratar de modo crítico e contundente as mazelas do social de Recife.

Como Jaguaribe afirmou anteriormente, as estéticas do realismo criam ficções que intensificam, selecionam e enquadram personagens e/ou eventos para este fim. Aqui, temos uma realidade que pertence ao cotidiano, como o próprio cineasta comenta em entrevista. Entretanto, é apresentada ao espectador de forma intensificada - o diretor coloca em uma mesma situação sangue, carne, sujeira, a textura do prédio carcomido pelo tempo, trabalhadores sujos

101 PORTO ALEGRE | v. 19 | n. 31 | 2014 | pp. 96-106 Sessões do Imaginário 
de sangue, aparentemente despreparados para realizarem a tarefa que executam - buscando provocar o pancadão do real.

Nessa sequência, Assis coloca, na tela, trabalhadores sem equipamentos de segurança, em um ambiente de trabalho totalmente insalubre, e aparentemente resignados e/ou indiferentes a isto - trabalham tranquilamente em meio à sujeira, com instrumentos inadequados, sujeitando-se a possíveis acidentes e/ ou doenças. A forma como esse ambiente é revelado ao espectador pode provocar uma sensação de desconforto, repulsa, náusea, impactando-o ao mostrar o lado primitivo da natureza humana, remetendo à violência e à agressividade vinculadas à necessidade de sobrevivência. Essa sequência introduz a questão da dicotomia vida e morte. Temos aqui homens utilizando seus impulsos agressivos, socialmente aceitos, para sobreviver. Para Alencar (2008, p. 190), este seria um "espetáculo violento de preparação das refeições".

\section{Sequência 24 - O homem perdido ${ }^{5}$}

Lígia, sem nada dizer, sobe numa cadeira e depois numa mesa. Em seguida levanta sua saia. O público do bar começa a ovacionar a atitude dela, que, ainda encarando Isaac, abaixa a saia e desce da mesa (Lacerda, 2002, p. 39).

Lígia mora e trabalha no Bar Avenida. Trata-se de um bar de subúrbio, humilde, de paredes verdes com a pintura já bem desgastada, grande placa amarela com os preços, fardos de refrigerante empilhados. Ao fundo, atrás do balcão, uma grande imagem de São Jorge. É horário de almoço e alguns fregueses comem, outros apenas bebem, outros dançam ao som da música que vem da velha jukebox.

Lígia caminha por entre as mesas atendendo seus clientes e Isaac pede mais uma cerveja. Quando coloca a cerveja sobre a mesa e retira a tampa com um grande abridor de madeira, Isaac pergunta a ela: “Todos os seus cabelos são dessa cor ou a moça só tem grana pra pintar os da cabeça?".

Como resposta, Lígia coloca o abridor no queixo de Isaac para erguer-lhe o rosto e sobe na cadeira que está diante dele; coloca uma das pernas sobre a mesa e levanta o vestido, mostrando a ele seu púbis loiro (Figura 2). Baixa o vestido, desce da cadeira e volta para trás do balcão, enquanto Isaac a olha estupefato e os demais clientes, aplaudem entusiasmados.

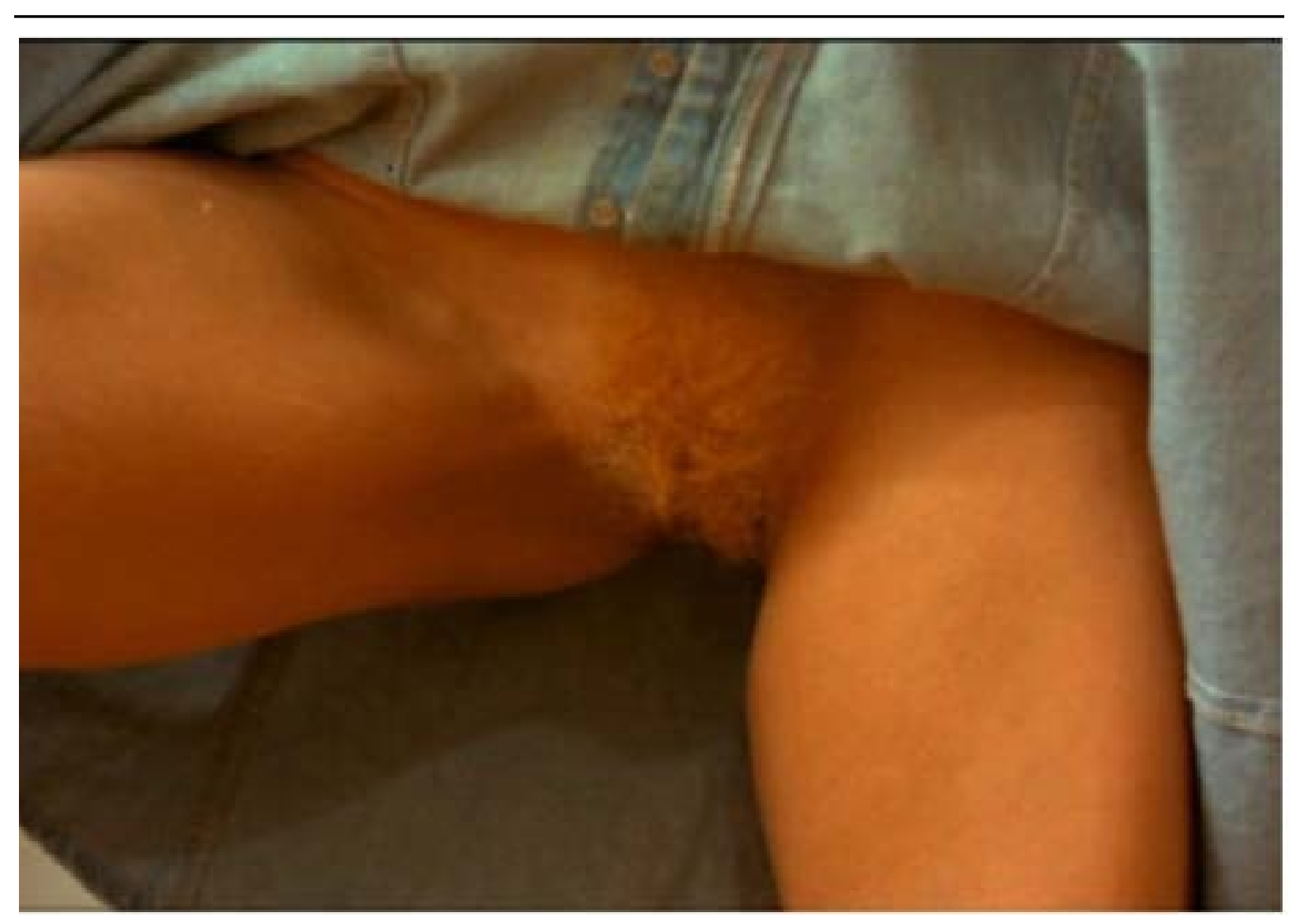

102 PORTO ALEGRE | v. 19 | n. 31 | 2014 | pp. 96-106 Sessões do Imaginário

Figura 2:

Cena da sequência Ohomem perdido 
Conforme assinala Jaguaribe (2007, p. 123), o enquadramento realizado por Assis no pelo púbico mostra ao espectador um irônico "choque do real" que evoca o pintor francês, Gustave Courbet em As origens do mundo, 1866 (Figura 3). Segundo colocações da autora, no momento em que o cineasta apresenta o sexo feminino fora do modelo erótico costumeiro, oferecendo ao espectador uma visão desconcertante, estranha do "real", está utilizando um recurso de desfamiliarização. Recurso este de grande importância para provocar o "choque do real".

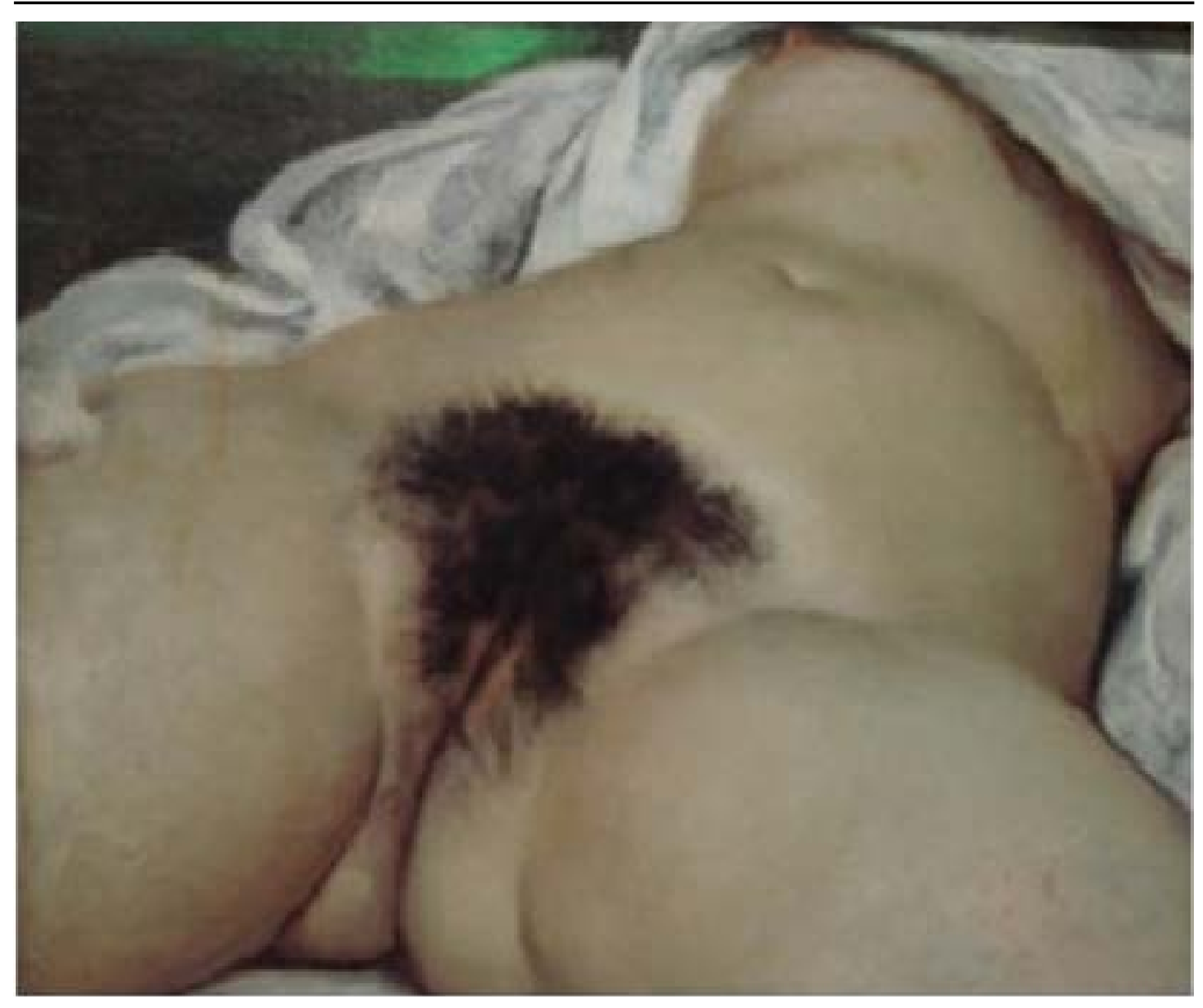

Figura 3: As

origens do

mundo, do pintor

Gustave Courbet através de um sítio de relacionamentos na internet. [...] a selvageria da ação, do assassinato [...] no filme, é exposto para acentuar a realidade" (Gasparelli Junior, 2008, p. 100). Como nos diz Jaguaribe (2007), é o reforço do real, através do excesso nas imagens.

O cineasta retrata a violência que ocorre diariamente, muito próxima de todos nós, sem que dela tomemos consciência. Afinal, partes do animal morto, logo estarão em diversas casas, servindo de alimento. Trata-se da violência diária e costumeira presente nas cidades. O que também enfatiza este caráter usual é a postura dos trabalhadores; eles simplesmente estão trabalhando, executando uma tarefa diária, envolta em violência, sangue, morte. Sob o prisma de Jaguaribe (2007), Assis retrata um evento cotidiano utilizando códigos realistas com o intuito de sensibilizar, causar desconforto ao espectador, provocando o que a pesquisadora denomina pancadão do real. Para ela, ao investir no caráter documental de sua câmera, o cineasta potencializa estilisticamente o choque do real, provocando no espectador, no mínimo, dois tipos diferentes de impacto: o de assistir o desenrolar de uma ação violenta e o de ver esta ação sendo registrada ao vivo.

Através de sua câmera documental, o cineasta apresenta ao espectador uma cena de 1 minuto e 5 segundos de duração para retratar uma atividade cotidiana. A cena mostra o processo de abate em si. Um funcionário golpeia a cabeça de um boi que se encontra encurralado. Após, mais dois funcionários ajudam a arrastá-lo para o local onde será eviscerado e desmembrado deixando, ao longo do percurso, um rastro de sangue. Com o animal ainda vivo, começam a abrir-lhe o peito com uma grande faca. $\mathrm{O}$ sangue se espalha pelo chão. A câmera, em constante movimento, 
se afasta para que os homens e sua carga possam passar; aproxima-se do animal agonizando, mostrando a morte de perto e de frente, em close (Figura 4).

Aqui, pelo enquadramento, o espectador se vê diante da grande tela preenchida pela imagem de um animal, imobilizado e agonizante, provocando o que

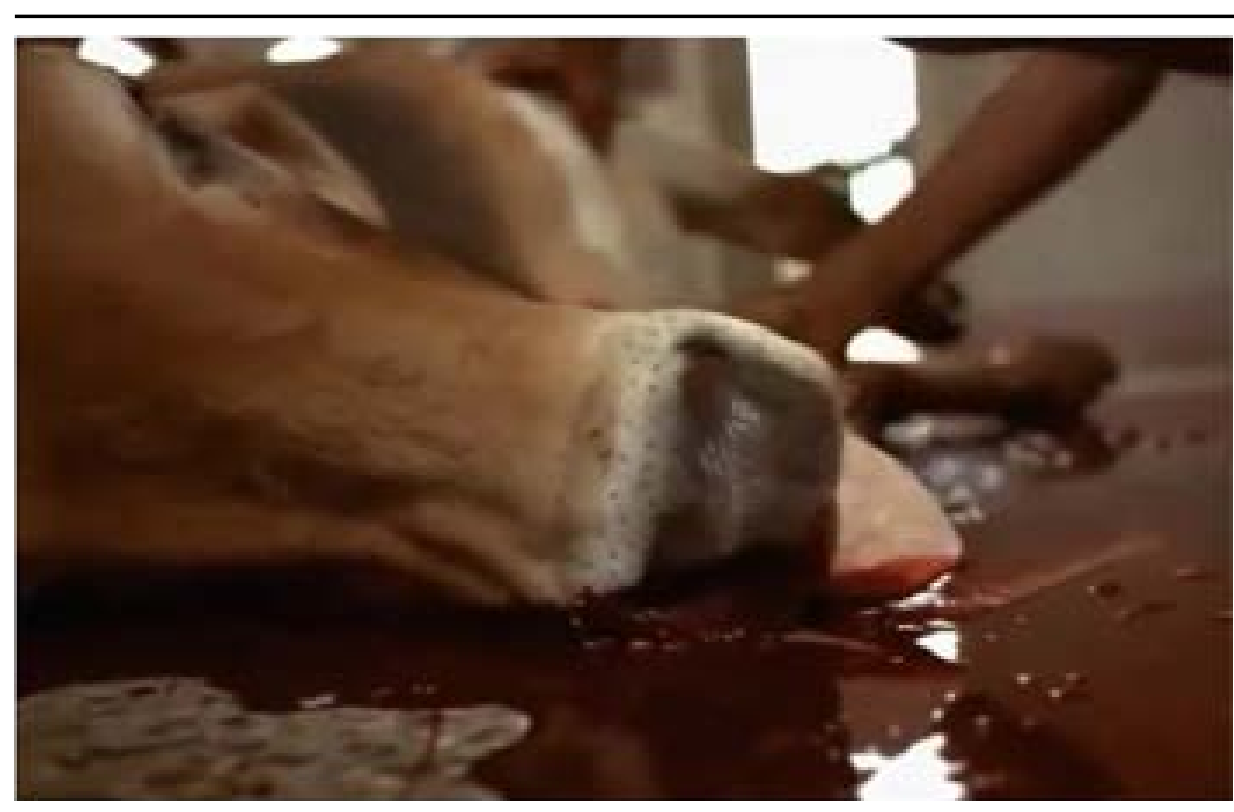

Figura 4: Close

no momento do

abate de um ani-

mal em Amarelo

manga

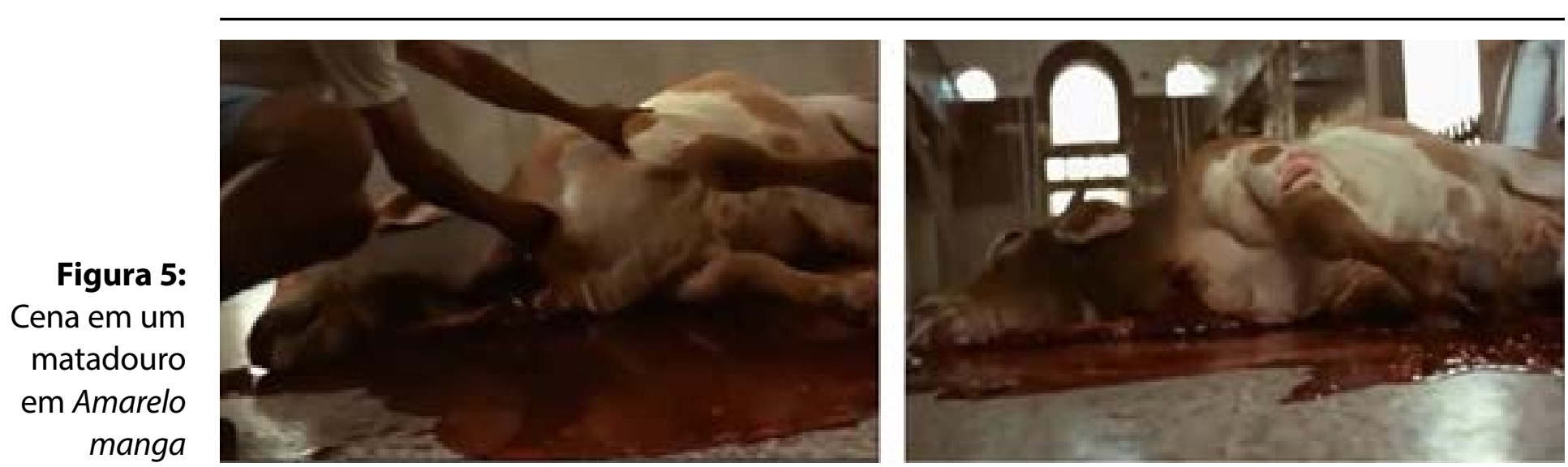

Tomando por base as reflexões de Beatriz Jaguaribe, podemos dizer que Cláudio Assis, em Amarelo manga, utiliza histórias, personagens e eventos cotidianos, apresentados de forma verossímil e convincente, sensibilizando o espectador, causando desconforto, incômodo. Apoiando-se em códigos realistas, mostra sem pudores uma realidade violenta que está encravada em nossas grandes cidades. Conforme ele mesmo diz, "quero mostrar a realidade como ela é".

Mesclando cenas ficcionais e documentais, o diretor produz uma ficção com uma realidade plausível, permeada de "efeito do real", apresentando narrativa que oferece uma intensidade do real maior do que a absorvida no dia a dia. Com imagens perturbadoras, retrata uma Recife violenta, sórdida e desigual.

A vida cotidiana é ficcionalizada e estetizada, sendo um exemplo do que Jaguaribe chama de "pancadão do real", de retrato contundente da realidade. Repleto de momentos que proporcionam descargas catárticas, o realismo utilizado por Assis atua como elemento que reforça o desnudamento dessa mesma realidade.

Para exacerbar cenas da violência urbana que passariam despercebidas, o diretor escolhe e articula de forma precisa elementos da linguagem cinematográfica tais como enquadramentos, movimentos de câmera, cores, texturas, dentre outros. É clara a sua intenção de sensibilizar o espectador, buscando retirá-lo de sua neutralidade, provocar sensações de incômodo, desconforto, repulsa, ou mesmo despertar pensamentos críticos.

Amarelo manga não é um filme do qual o espectador saia impune.

104 PORTO ALEGRE | v. 19 | n. 31 | 2014 | pp. 96-106 Sessões do Imaginário 


\section{Referências}

ALENCAR, Marlivan Moraes de. Imagens da metrópole no cinema brasileiro. 2008. 350f. Tese (Doutorado em Ciências Sociais) - Faculdade e Ciências Sociais da PUC-SP, São Paulo, 2008. Disponível em: <http://www.sapientia. pucsp.br//tde_busca/arquivo.php?codArquivo=7265 >. Acesso em 25 out. de 2012.

ASSIS, Cláudio. Entrevista com Cláudio Assis. Contracampo Revista de Cinema, São Paulo, n. 54, 2003, on-line. Entrevista concedida a Cléber Eduardo. Disponível em: <http://www.contracampo.com.br/52/ entrevistaclaudioassis.htm>. Acesso em: $10 \mathrm{dez} .2011$.

Cláudio Assis continua indomável. Revista de Cinema, 15 dez. 2011, on-line. Entrevista concedida a Julio Bezerra. Disponível em: <http://revistadecinema. uol.com.br/index.php/2011/12/claudio-assis-continuaindomavel/ >. Acesso em: 23 nov. 2012.

$\mathrm{O}$ anarco cineasta. Revista Cult, Sumaré, $\mathrm{n}$. 159, jul. 2011, on-line. Entrevista concedida a Eduardo Simões. Disponível em: <http://revistacult.uol.com.br/ home/2011/07/o-anarco-cineasta/>. Acesso em 04 de out. de 2012.

BARTHES, Roland. El efeito do real. In: Realismo: mito, doctrina o tendência histórica? Buenos Aires: Lunaria, 2002 , pp. $75-82$.

FONSECA, Nara Aragão. Da lama ao cinema: Interfaces entre o cinema e a cena mangue em Pernambuco. 2006. 125f. Dissertação (Mestrado em Comunicação) -

Centro de Artes e Comunicação, Universidade Federal de Pernambuco, Recife, 2006. Disponível em:<http:// www.cinemapernambucano.com.br/trabacademicos/ dalamaaocinema.pdf >. Acesso em: 10 nov. 2012.

FRUS, Phyllis. The politics and poetics of journalistic narrative. Cambridge: Cambridge University, 1994.

GASPARELLI JÚNIOR, Luiz Guaracy. A lâmina do naturalismo e seus códigos arquetípicos no cinema brasileiro contemporâneo. 2008. 136 f. Dissertação (Mestrado em Ciência da Arte) - Instituto de Arte e Comunicação Social, Universidade Federal Fluminense, Niterói. 2008. Disponível em: <http://www.uff.br/ cienciadaarte/dissertacoes/2008_luiz_guaracy_g_ junior.pdf >. Acesso em: 05 nov. 2012.

JAGUARIBE, Beatriz. O Choque do Real a violência e as estéticas do realismo midiático e literário. Revista Semiosfera, Rio de Janeiro, número especial, dez. 2003, on-line. Disponível em: <http://www.semiosfera. eco.ufrj.br/anteriores.htm>. Acesso em: 26 out. 2012.

O choque do real: estética, mídia, cultura.

Rio de Janeiro: Rocco, 2007.

Choque do real. Entrevista com a ensaísta Beatriz Jaguaribe. Blog Luiz Zanin - Cinema, cultura \& afins, 21 out. 2007, on-line. Entrevista concedida a Luiz Zanin. Disponível em: <http://blogs.estadao.com.br/ luiz-zanin/choque-do-real/>. Acesso em: 26 out. 2012.

LACERDA, Hilton. Roteiro do filme Amarelo Manga. Disponível em: <http://www.roteirodecinema.com.br/ roteiros/amarelo_manga.pdf>. Acesso em: 02 jun. 2012.

\section{Referências audiovisuais}

ASSIS, Cláudio. Amarelo manga. [Filme-vídeo]. Produção de Cláudio Assis e Paulo Sacramento, direção de Cláudio Assis. Brasil, 2003. 101 min. color. son.

BABENCO, Hector. Carandiru. [Filme-vídeo]. Produção e direção de Hector Babenco. Brasil, 2003. 145 min. color. son.

BRANT, Beto. $\mathbf{O}$ Invasor. [Filme-vídeo]. Produção de Bianca Villar e Renato Cisca, direção de Beto Brant. Brasil. 2002. 97 min. color. son.

MEIRELLES, Fernando. Cidade de Deus. [Filme-vídeo]. Produção de Walter Salles, direção de Fernando Meirelles. Brasil. 2002. 130 min. color. son.

PADILHA, José. Ônibus 174. [Filme-vídeo]. Produção de José Padilha e Marcos Prado, direção de Felipe Lacerda e José Padilha. Brasil. 2003. 133 min. color. son.

\section{Notas}

1. Mestranda em Comunicação Social pela Pontifícia Universidade Católica do Rio Grande do Sul (PPGCOM/PUCRS - Av. Ipiranga, 6681, Prédio 7, Sala 319, Porto Alegre-RS, Brasil, CEP: 90619-900). E-mail: gilkavargas@gmail.com

2. "[...] a arte [...] tem por objetivo transmitir a experiência imediata de alguma coisa como ela é vista e não como é reconhecida, a arte tem como finalidade tornar as coisas estranhas" (Sklorskij apud Jaguaribe, 2003, on-line). 
3. Assis, em entrevista à revista Cinemais, relata que cada um de seus dramas foi inspirado em fatos reais; alguns vividos por ele próprio, outros tirados de notícias de jornais (Alencar, 2008, p. 174).

\section{Nomeada conforme consta no roteiro.}

5. Nomeada conforme consta no roteiro.

6. Cena documental que não consta no roteiro e que foi inserida entre a sequência 25 e 26. 